\section{Multinomial Logistic Regression Model to Identify Factors Associated with Food Insecurity in Rural Households in Nepal}

\author{
Santosh Kumar Shah
}

Submitted: 30 June 2020; Accepted: 19 October 2020

Published online: 18 December 2020

DOI: https://doi.org/ / 0.3 I 26/njs.v4i0.33448

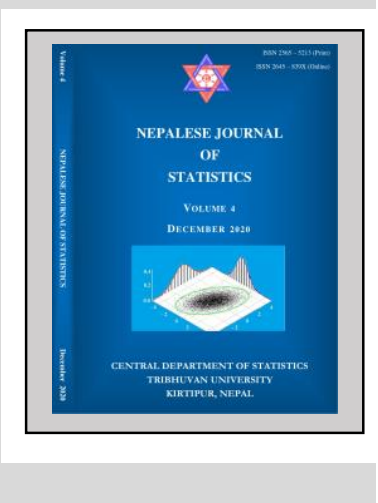

\title{
ABSTRACT
}

Background: Food is basics of our lives and many people experiences food insecurity at some time because of food deprivation and lack of access to food due to different resource constraints. It is a global challenge and threatens the rural people in developing countries like Nepal. Objective: The objective of the study is to identify the factors associated with food insecurity in rural area of Nepal.

Materials and Methods: The analysis is based on rural household data extracted from the data of Nepal Demographic and Health Survey 2016. The dependent variable food insecurity status was measured in four levels namely food secure, mildly food insecure, moderately food insecure and severely food insecure household using Household Food Insecurity Access Scale. Independent variables were categorical and quantitative variables. In order to identify the factors associated with food insecurity, ordinal logit model was fitted initially. Due to violation of test of parallel lines by overall as well as some of the independent variables, multinomial logistic regression model was finally adopted by examining the model adequacy test.

Results: The fitted multinomial logistic regression satisfied the diagnostic test including tests of goodness of fit, multicolinearity diagnostic criteria and minimum criteria of utilization of the model with about $29 \%$ predictive power. The variables ecological region, wealth index, size of agriculture land, any member(s) having saving account in any financial institution, any member(s) had gone to foreign employment in last 5 years other than India, family size, number of members completed secondary education and household member rearing cattle(s) were found to be significant. The poorest households (HHs) had 3.14 (Cl: I.88-5.26) times, poorer $\mathrm{HHs} 2.5 \mathrm{I}$ ( $\mathrm{Cl}$ : 1.55-4.07) times and moderate $\mathrm{HHs} \mathrm{I} .42$ times higher chances of being severely food insecure relative to rich $\mathrm{HHs}$. Conclusion: The study revealed that food insecurity of the rural $\mathrm{HH}$ increases with decrease in the wealth index, size of land and number of members of the HHs with completed secondary education. The food insecurity of the households decreases with increase in the access to bank service.

Keywords: Food insecurity, multinomial logistic regression, ordinal logit model. 
Address correspondence to the author: Central Department of Statistics, Tribhuvan University, Kirtipur, Kathmandu, Nepal. E-mail: santoshshahI234@yahoo.com

\section{INTRODUCTION}

Food is an essential part of our lives and many people experiences food insecurity at some time in a given year because of food deprivation and lack of access to food due to economic resource constraints. It is a global problem that the world is facing and is struggling to address since decades back but still far away from a decisive success. Despite of the progress on the indicators of food insecurity, almost 800 million people are chronically hungry and about 2 billion suffer micronutrient deficiencies. It further predicts that if no additional efforts are made, the problems become more horrible in 2030 (Food and Agriculture Organization [FAO], 2017). Compared to other regions, the burden of hunger occurs in South Asia is peak, where as many as 28I million people are undernourished. However, the progress towards the indicators of food security and nutrition has been slow in South Asia and sub-Saharan Africa (FAO, 20I5).

Food security is a difficult concept to measure since it deals in very broad terms with the production, distribution and consumption of food. World food summit defines food security that had gained the wide acceptance is "the situation that exists when all people, at all times, have physical, social and economic access to sufficient, safe and nutritious food which meets their dietary needs and food preferences for an active and healthy life" (FAO, 2006). It covers the four dimensions-accessibility, availability, utilization and stability of food security. The definition contains the economic as well as the physical aspects of food availability and attention was drawn to alleviate poverty. This has been widely applicable from global level to individual level. At household level, a household is considered to be food secure when every member of the household has year-round access to the amount and variety of safe foods and their members need to lead active and healthy lives (FAO, 2010). The components that may guide to a situation of food insecurity include nonavailability of food, lack of access, improper utilization and instability over a certain time period.

People can secure their foods either through their own production or through purchasing. Nepal is largely met by domestic production (Pant, 2013) and depends heavily on food imports primarily from India and other countries. On the other hand, due to the complex geography, low production, lack of resources and infrastructure including transportation particularly in rural Hill and Mountain area, and in remote Terai, it makes them more vulnerable to price volatility. People have to spend more of their income on food. A study reveals that people living in rural Hill and Mountain regions spend up to $78 \%$ of their income on food (World Food Programme [WFP] \& Nepal Development Research Institute [NDRI], 20I0). Food insecurity and hunger are a part of daily life problems especially for the families living in Nepal's remote highland regions of Nepal. 
Despite of enshrining food as a fundamental right of every citizen by the constitution of Nepal 2015, Nepal is one of the most food insecure countries in the world and ranks $79^{\text {th }}$ among 113 countries (Global Food Security Index [GFSI], 2019). Agriculture production is important for food security especially for rural people not for production only but it also provides the primary sources of livelihood to $36 \%$ of the world's total workforce (International Labour Organization [ILO], 2007). Even in Nepal, it provides the livelihood to more than $60 \%$ of the people (Central Bureau of Statistics [CBS], 2017). However, the agriculture productions are largely affected in Nepal due to different constraints including poor technology, climate variability and poor market. As a result, still $11.7 \%$ of the rural people had suffered from severely food insecure and $26 \%$ moderately food insecure (Ministry of Health $[\mathrm{MoH}]$ et. al., 2017). A food security is multidimensional and flexible concept and so many methods such as income and expenditure, and caloric adequacy basis have been used for measuring it. Nepal Demographic Health Survey (NDHS), 2016 uses Household Food Insecurity Access Scale (HFIAS) which is the qualitative methods for measuring people's perception and people's experience of facing food insecurity developed by Food and Nutrition Technical Assistance of USAID (MoH et. al., 2017). A study conducted on rural area of Pakistan and another conducted in eastern Nepal reveals that sex of the household head played a dominant role in food insecurity as women-headed household was at higher risk of insecurity compare to men-headed households (Quinonez \& Hackett, 2008; Joshi \& Joshi, 2016; Abdullah et al., 2019; Kassie et al., 2014) although they play major role in household including cooking food. The study conducted on Zambia concluded that higher education levels of household head, increasing livestock incomes, secure land tenure, increasing land size, and group membership decreases the risk of household food insecurity (Nkomokiet, et al., 2019). A study conducted in eastern Nepal reported that the households with bigger size of land holding contributed positively to food security whereas larger household size affected negatively to the food security (Joshi \& Joshi, 2016).

The major objective of this study is to identify the factors associated with food insecurity in rural household in Nepal. Moreover, the paper is focused on identifying the socio-economic and demographic risk factors associated with food insecurity through the use of appropriate statistical model.

\section{MATERIALS AND METHODS}

\section{Data}

The data of Nepal Demographic and Health Survey (NDHS), 2016 was used for this study. It is the fifth national representative survey conducted in Nepal as part of the worldwide Demographic and Health Survey Program (MoH et al., 20 I6). Out of the data of II,040 households, 4,062 rural households were retrieved initially from the data set. However, the data of 404I households were only analyzed for this study. The remaining $2 \mathrm{I}$ cases were omitted because these households were responded "I did not know" in the question "How many bigha/ropani of agricultural land do members of this household own?". The study is focused on the household food 
insecurity; thus, the unit of analysis is the household. Details of the survey procedure and sampling design are available in the NDHS report (MoH et al., 2016).

\section{Variables}

The dependent variable is food insecurity status which is measured by Household Food Insecurity Access Scale (HFIAS) using 9 questions under the headings of "Household Food Security" in NDHS questionnaire. The 9 questions were presented in four-point scale. Based on the HFIAS indicator guide and responses on these 9 questions, food insecurity status is categorized into - food secure, mildly food insecure, moderately food insecure, and severely food insecure households (Coates et al., 2007). It is measured in ordinal scale. The internal consistency reliability of the items of the food insecurity scale was measured through Cronbach alpha. The value was found to be 0.878 indicates good internal consistency between the items (Habidin et al., 20I5).

Based on the literature review, number of independent variables including categorical as well as quantitative were taken into account. These variables were family size, ecological zone (Mountain/Hill/Terai), sex of the household head (men/women), age of the household head, any members having saving account in financial institution (yes/no), wealth index (poorest/poorer/ middle/richer and richest), number of members completed secondary education, size of own agriculture holding (no land/less than $0.3 \mathrm{Ha} /$ more than $0.3 \mathrm{Ha}$ ), $\mathrm{HH}$ rearing cattle including cows, bulls, buffalo (yes/no) in a household, any person had gone for employment in last 5 years other than India (yes/no). The independent variable, any member(s) having saving account in financial institution (yes/no) is taken as proxy variable of access to financial institution.

\section{Data analysis}

Descriptive analysis was carried out to assess the nature and characteristics of dependent variable and independent variables. The estimated value of the parameters and their standard errors with and without using sample weights in the model were found similar. Hence sample weights were not considered in the entire analysis. Ordinal logit model was used initially and proportional odds assumptions were tested. The LR test is an omnibus test also revealed that model violated the assumption. Literatures show that the proportional odds assumption is satisfied seldom in practice. Thus, further analysis is necessary to identify how many and which variable do not satisfy the assumption. Brant's Wald test statistic was used to test the proportionality assumption both in an omnibus and individual manner (Brant, 1990). It was found that the assumptions were violated for some of the independent variables. Finally, a multinomial logistic regression model was developed to establish the relationship between household food insecurity and the significant factors. Concerning to the reference of categorical variable in the model, higher order category was considered as the reference in both outcome variable and explanatory variables such that odds ratio can be interpreted as the risks of getting household food insecurity. 
Consider a random variable $Y_{i}$ that can take one of several discrete values of $j$ where $j=I, 2$, . . , $L$ and the response $L$ categories are mutually exclusive and exhaustive. Let $\Pi_{i j}$ denotes the probability that the $i$-th response falls in the $j$-th category that is $\Pi_{i j}=\operatorname{Pr}\left\{Y_{i}=j\right\} ; j=I, 2, \ldots$. . Thus, we have $\sum_{j=1}^{L} \pi_{\mathrm{ij}}=1$ for each $\mathrm{i}$ and there are only $\mathrm{L}-\mathrm{I}$ categories. Consider the multinomial logit model that is the models of log-odds for $M$ covariates associated with $\mathrm{i}$-th individual is given by:

$$
\ln \frac{\pi_{\mathrm{ij}}}{\pi_{\mathrm{iL}}}=\beta_{j 0}+\sum_{k=1}^{M} \beta_{j k} X_{i k} ; \quad j=1,2, \ldots L-1
$$

The above model also be written in terms of $\pi_{i j}$ as:

$$
\pi_{\mathrm{ij}}=\frac{e^{\beta_{j 0}+\sum_{k=1}^{M} \beta_{j k} X_{i k}}}{1+\sum_{j=1}^{L-1} e^{\beta_{j 0}+\sum_{k=1}^{M} \beta_{j k} X_{i k}}} ; j=1,2, \ldots L-1
$$

where $0 \leq \pi_{\mathrm{ij}} \leq 1, j=1,2, \ldots . L-1$ and $\mathrm{X}_{\mathrm{ik}}(\mathrm{i}=\mathrm{I}, 2, \ldots \mathrm{n} ; \mathrm{k}=\mathrm{I}, 2, \ldots \mathrm{M})$ are the explanatory variables. The parameters of the model $\beta_{j 0}$ and $\beta_{\mathrm{jk}}$ are estimated on the basis of the maximum likelihood estimation which follows Newton-Raphson iterative estimation method (Mc Cullagh \& Nelder, 1989; IBM knowledge center, 2016). The equation simultaneously describes the effect of $X$ on the above $L-I$ logits with respect to the reference category $L$. The effects might be varying according to the response paired and is calculated as:

where $r \neq s=1,2, \ldots L-1$.

$$
\frac{\pi_{\mathrm{ir}}}{\pi_{\mathrm{is}}}=\frac{\pi_{\mathrm{ir}}}{\pi_{\mathrm{iL}}}-\frac{\pi_{\mathrm{is}}}{\pi_{\mathrm{iL}}}
$$

\section{Model adequacy test}

Several measures of model adequacy tests have been considered in order to inspect how well the fitted models matched with observed data. The overall goodness of fit of the model was assessed through likelihood ratio test (LRT) which is based on the -2 Log Likelihood (LL). LRT produces a chi-square statistic to test the null hypothesis that there is no significant difference between the models without explanatory variables and the model with explanatory variables. The deviance and Pearson's chi-square were used to test the goodness of fit of the model. In this test, if $\mathrm{p}$-value $>0.05$, we fail to reject null hypothesis which indicates that there is no significant difference between observed and model predicted values, implying that the model estimates are adequate to fit the data at an acceptable level. The predictive power of the fitted model was used to measures the Pseudo $\mathrm{R}^{2}$. Higher pseudo $\mathrm{R}^{2}$ indicates that more of the variation is explained by the model.

As the correlation increases among the independent variables, the standard errors of the logit parameters will become inflated. Multicolinearity was assessed by computation of variance inflation factor (VIF) having threshold value 5. The likelihood ratio test was also used to test the individual independent variable that has significant effect on the outcome variable. Moreover, Wald statistic was used to test the significance of the estimated coefficient. If $p$-value $<0.05$, we reject the null 
hypothesis which means that particular coefficient is differ from zero and conclude that the respective independent variable has significant contribution on the particular category of outcome variable relative to reference category. The utility of the model was also evaluated by comparing the proportional by chance accuracy rate with classification overall percentage. If the classification overall percentage is improved by $25 \%$ chance accuracy rate, the model is useful (El-Habil, 20I2).

\section{RESULTS}

\section{Descriptive analysis}

Some descriptive analysis is executed by considering equal sample weight in order to examine the distribution of dependent variable and independent variables included in the model. Total I 1.6\% households were severely food insecure, $28.0 \%$ mild, $24.3 \%$ moderately and $36.0 \%$ were not food insecure that is food secure households (Table I).

Table I. Distribution of household food insecurity status.

\begin{tabular}{llrr}
\hline Variable & Description & Frequency & Percent \\
\hline \multirow{3}{*}{ Food insecurity } & Severely food insecure & 470 & $1 \mathrm{I} .6$ \\
status & Mild food insecure & $\mathrm{I}, 133$ & 28.0 \\
& Moderate food insecure & 982 & 24.3 \\
& Food secure & 1,456 & 36.0 \\
\hline & Total & $4,04 \mathrm{I}$ & 100.0 \\
\hline
\end{tabular}

Table 2 depicts the distribution of socio-economic and demographic characteristics of the respondents. Total samples distributed among Mountain, Hill and Terai were respectively $14.8 \%$, $48.8 \%$ and $36.4 \%$. Almost one third of the household were women-headed. About half of the households were belonging to the poor categories in the sample. Similarly, 41.2\% reported that no any members in the family had an account either in any banks, cooperative or other saving account. Further, $19.3 \%$ reported that at least one of the family members had gone for foreign employment other than India in the past 5 years. Total $10.8 \%$ household had not own agriculture holding and $26.2 \%$ did not have cattle including cow, buffalo and ox.

Table 3 illustrates the summary statistics of age of the household head, family size and number of members completed secondary education. The average age of the household head is 47.2 year ranging from 15 to 95 year. The age of the household head is approximately symmetrical whereas number of members completed secondary education in the household is positively skewed.

\section{Statistical modeling}

As the food insecurity status is the ordinal variable, ordinal logit model was fitted initially in order to identify the factors associated with food insecurity in rural area. Out of total covariates, only sex and age of household head were found insignificant during bivariate ordinal logit regressions whereas the covariates household having cattle found insignificant in multiple ordinal 
logit model. The variables ecological region, wealth index, size of agriculture land, any member(s) having saving account in any financial institution, any member(s) had gone to foreign employment in last 5 years other than India, family size and number of members completed secondary education were found significant in final multiple ordinal logit model. However, the likelihood ratio test ($2 L L=5700, p$-value $<0.01$ ) indicated that test of parallel lines was violated. In this test, null hypothesis states that the slopes of the estimated equations are identical.

Table 2. Distribution of general characteristics of the households.

\begin{tabular}{llrr}
\hline Variable & Description & Frequency & Percent \\
\hline \multirow{2}{*}{ Ecological region } & Mountain & 597 & 14.8 \\
& Hill & 1,973 & 48.8 \\
& Terai & 1,471 & 36.4 \\
\hline \multirow{2}{*}{ Sex of the HH head } & Women & 1,257 & 31.1 \\
& Men & 2,784 & 68.9 \\
\hline \multirow{4}{*}{ Wealth index } & Poorest & 1,068 & 26.4 \\
& Poorer & 951 & 23.5 \\
& Middle & 752 & 18.6 \\
& Richer/richest & 1,270 & 31.4 \\
\hline Saving account in financial & No & 1,664 & 41.2 \\
institution & Yes & 2,377 & 58.8 \\
\hline \multirow{2}{*}{ Foreign employment } & No & 3,262 & 80.7 \\
& Yes & 779 & 19.3 \\
\hline \multirow{2}{*}{ Size of own agriculture } & No land & 436 & 10.8 \\
holding & $<0.3$ Ha & 1,683 & 41.6 \\
& $>0.3$ Ha & 1,922 & 47.6 \\
\hline \multirow{2}{*}{ Rearing cattle } & No & 1,058 & 26.2 \\
& Yes & 2,983 & 73.8 \\
\hline & Total & 4,041 & 100.0 \\
\hline
\end{tabular}

Table 3. Summary statistics of household characteristics of quantitative variables.

\begin{tabular}{lcccc}
\hline Variable & Mean & $\begin{array}{l}\text { Standard } \\
\text { Deviation }\end{array}$ & Min & Max \\
\hline Age of household head & 47.22 & 14.72 & 15.00 & 95.00 \\
\hline $\begin{array}{l}\text { Number of members } \\
\text { completed secondary education }\end{array}$ & .43 & .80 & .00 & 9.00 \\
\hline Family size & 4.61 & 2.32 & 1.00 & 21.00 \\
\hline
\end{tabular}

Further, Brant's Wald test statistic considered to be more valid (Dolgun \& Saracbasi, 2014) was used to test the proportionality odds assumption both in an omnibus and individual manner. Table 4 shows the output of Brant test of parallel regression assumption in which null hypothesis 
states that the coefficients obtained from 3 binary logistic regression models namely (i) severely food insecurity verses moderately, mild food insecurity and food security, (ii) severely and moderately food insecurity verses mild food insecurity and food security and (iii) severely, moderately and mild food insecurity verses food security would be the same across equations except for sampling variability. The variables ecological region of hill category, wealth index of poorest and poorer categories, any member(s) having saving account in any financial institution and household rearing cattle violated the proportional odds assumption at $10 \%$ level of significance. It further reveals that proportional odds assumption was also violated for overall model. Hence, multinomial logistic regression model, considered to be a less restrictive, was used as an alternative model.

Further, the maximum likelihood estimator was used to estimate the coefficients of multinomial logistic regression model. Bivariate multinomial logistic regression models were carried out for each independent variable with food insecurity and found that all considered variables except age of household head were significant. Further, multiple multinomial logistic regression was finally carried out using significant variables. Stepwise method was adopted for selection of variables. Both the forward and backward likelihood ratio method provides the same significant covariates. The significance of the covariates was examined through - 2 LL statistic and likelihood ratio test. The covariates ecological region, wealth index, size of agriculture land, any member(s) having saving account in any financial institution, any member(s) went to foreign employment in last 5 years other than India, family size, and number of members completed secondary education were found significant with $\mathrm{p}$-value $<0.00 \mathrm{I}$ whereas covariate household member(s) rearing cattle with $\mathrm{p}$-value $<0.05$. Table 5 illustrates the odds ratios and their confidence intervals and $\mathrm{p}$-value of the response variables for each category. 
Table 4. Brant test of parallel regression assumption.

Variable Description Chi-square P-value

\begin{tabular}{|c|c|c|c|}
\hline Overall & & 54.91 & $<0.001$ \\
\hline \multirow{3}{*}{ Ecological region } & Mountain & 4.54 & 0.103 \\
\hline & Hill & 7.40 & 0.025 \\
\hline & Terai (R) & & \\
\hline \multirow{4}{*}{ Wealth index } & Poorest & 7.67 & 0.022 \\
\hline & Poorer & 4.97 & 0.083 \\
\hline & Middle & 2.61 & $0.27 \mid$ \\
\hline & Richer/richest (R) & & \\
\hline \multirow{2}{*}{$\begin{array}{l}\text { Saving account in } \\
\text { financial institution }\end{array}$} & No & 4.66 & 0.097 \\
\hline & Yes (R) & & \\
\hline \multicolumn{2}{|l|}{ Family size } & 0.98 & 0.614 \\
\hline \multicolumn{4}{|c|}{ No. of members completed secondary } \\
\hline education & & 0.52 & 0.772 \\
\hline \multirow{2}{*}{$\begin{array}{l}\text { Foreign } \\
\text { employment }\end{array}$} & No & 3.13 & 0.209 \\
\hline & Yes (R) & & \\
\hline \multirow{3}{*}{$\begin{array}{l}\text { Size of agriculture } \\
\text { holding }\end{array}$} & No land & 3.48 & 0.176 \\
\hline & $<0.3 \mathrm{Ha}$ & 3.04 & 0.219 \\
\hline & $>0.3 \mathrm{Ha}(\mathrm{R})$ & & \\
\hline \multirow{2}{*}{ Rearing cattle } & No & 8.61 & 0.013 \\
\hline & Yes (R) & & \\
\hline
\end{tabular}

$\mathrm{R}=$ Reference category. 
Table 5. Fitted model explaining the level of food security.

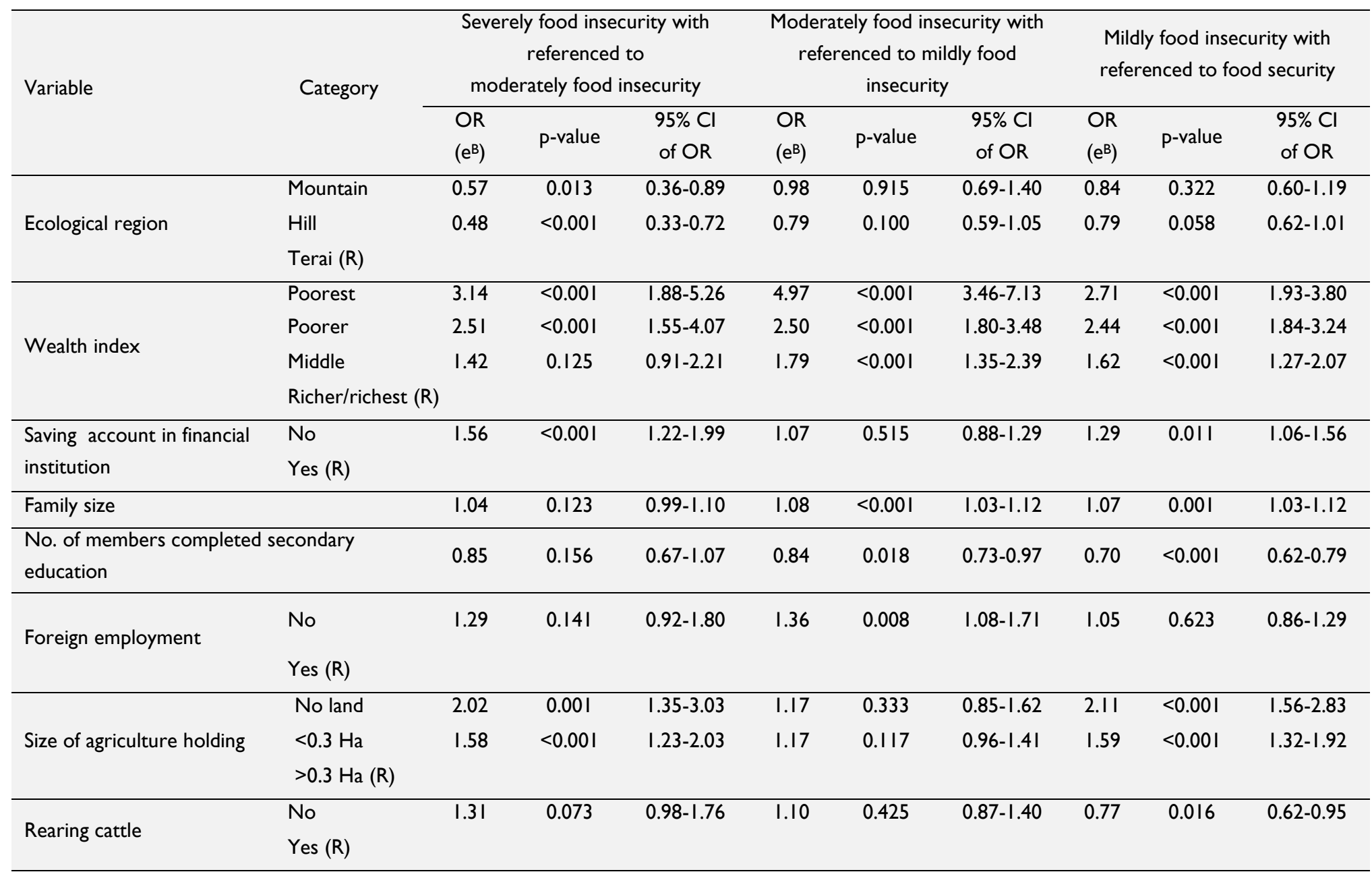

$\mathrm{OR}=$ Odds ratio; $\mathrm{Cl}=$ Confidence Interval; and $\mathrm{R}=$ Reference category. 
The odds ratio of the people living in the Mountain and Hill region for severe household food insecurity relative to moderate is $0.57(\mathrm{Cl}: 0.36-0.89)$ and $0.48(\mathrm{Cl}: 0.33-0.72)$ respectively compared to Terai. This means that the people who were living in Mountain region had $43 \%$ and Hill region $52 \%$ less chances that their $\mathrm{HHs}$ of being severely food insecure relative to moderately food insecure compared to the people living in Terai region. The odds ratios of poorest and poorer households as compared to richest for the model severely food insecurity against moderately food insecure are $3.14(\mathrm{Cl}$ : I.88-5.26) and $2.5 \mathrm{I}(\mathrm{Cl}$ : I.55-4.07) respectively. This depicts that the poorest $\mathrm{HHs}$ had 3.14 times and poorer had 2.5I times higher chances of being severely food insecure relative to moderate food insecure. Similarly, comparing moderately food insecure with reference to mildly food insecure, poorest $\mathrm{HHs}$ had 4.97 times, poorer 2.50 times and middle 1.79 times more likely to be moderately food insecure relative to mildly food insecure. Moreover, poorest $\mathrm{HHs}$ had 2.7 I times, poorer 2.44 times and middle 1.62 times more chances to be mildly food insecure relative to food secure $\mathrm{HHs}$.

The odds of being severely food insecure relative to moderate food insecure among the $\mathrm{HHs}$ whose member(s) had not a saving account in any financial institution including commercial, development, microfinance and cooperative had 1.56 times higher than those having a saving account. Similarly, the HHs whose member(s) had not a saving account had $1.29 \%$ higher chance of being mildly food insecure relative to food secure. The odds ratio of family size for moderate food insecurity with reference to mild food insecurity $(\mathrm{OR}=1.08, \mathrm{Cl}$ : 1.03-1.12) and mild food insecurity to food security $(\mathrm{OR}=1.07, \mathrm{Cl}$ : I.03-I.I2) were found statistically significant. This means with per unit increase in the member in the household had increased the risk of being moderate and mild food insecurity. Similarly, the odds of being moderate food secure relative to mild and mild food insecurity to food security were decreased by $16 \%$ and $30 \%$ respectively with per additional member completed secondary education.

The chances of being moderate food insecurity relative to mild food insecurity was I.36 times more with none of the member had gone for foreign employment other than India in last five years compare to those households whose at least one member(s) had gone to foreign employment. Similarly, odds of mild food insecurity relative to food security was $23 \%$ less of those family which had not reared cattle compare to those which reared cattle. On the subject of size of agriculture holding, the risk of having severely food insecure households relative to moderate, and mildly food insecure to food secure household was double of those households which had not an agriculture holding compare to those which had more than $0.3 \mathrm{Ha}$ land. Similarly, the chances of having severely food insecure relative to moderate, and mildly food insecure to food secure was respectively 1.58 and 1.59 times higher of those households which had less than $0.3 \mathrm{Ha}$ compared to more than $0.3 \mathrm{Ha}$ of land. Concerning the overall fit of the model, likelihood ratio test reveals that model with explanatory variables and without explanatory variables was significantly different $\left(\chi^{2}=1245 ; p\right.$-value $\left.<0.001\right)$. This means explanatory variables had significant effect on outcome 
variable. In addition, Pearson and deviance chi square test was found to be not significant ( $P$-value $>0.63$ ), that depicts that model estimates are adequately fit the data.

The VIFs of all covariates were found to be less than 3, which indicates that there is no multicolinearity between the covariates. The predictive power of the fitted model is $28.6 \%$ assessed through Nagelkerke $\mathrm{R}^{2}$ (pseudo $\mathrm{R}^{2}$ ). This shows that $28.6 \%$ of the variation in the dependent variable is explained by the model. Regarding the utility of the model, classification overall percentage $(47.2 \%)$ is increased by $65 \%$ compare to chance accuracy rate $(28 \%)$ which shows that the fitted model is useful.

\section{DISCUSSION}

The outcome variable food insecurity is polychotomous and measured in ordinal scale. Thus, ordinal logistic regression is the most preferred model that was used instead of binary logistic regressions and multinomial logistic regression. Ordinal logistic regression provides single odds ratio or coefficient for each explanatory variable and assumes that the explanatory variables have the same effect on the odds regardless of the threshold. The assumption is known as proportional odds assumption. In this study, Brant test clearly revealed the test was violated for some of the explanatory variables. Thus, in this scenario, multinomial logistic regression is considered to be better than ordinal logistic regression model. The multinomial logistic regression explores the factors associated with food insecurity status. Total 8 factors out of 10 were significant predictors that change the probability of food insecure $\mathrm{HHs}$ to food secure $\mathrm{HH}$. The sex and age of the $\mathrm{HH}$ heads were found insignificant with food insecurity. On contrary to this result, many studies reported that sex is the significant predictor of food insecurity (Quinonez \& Hackett, 2008; Joshi \& Joshi, 2016; Abdullah et al., 2019; Kassie et al., 2014). One of the reasons of obtaining this difference might be that the most of the household changes from men-headed to women just because her husband departing to work elsewhere. Poverty trends in Nepal reported that $65 \%$ of the female-headed households received remittances, in contrast to only $24 \%$ of male-headed households (CBS 2005).

Despite of fertile farmland and better transportation facilities, the people living in Terai region had significantly greater risk of being severely food insecure over moderate food insecure households compared to the people living in Hill and Mountain regions. However, the result was not significant in moderately food insecure against mild food insecure and mild food insecure against not food insecure households. This clearly indicates that the lower class of Terai people were more influenced compared to Hill and Mountain. This might be due to lack of people's ability to afford food. In other word, the people living in Terai were rich in physical access to food and they might have poor economical access. The statement was also justified by the fact that mean and median nominal per capita income of Terai people was lesser than Hill and Mountain (CBS, 2004). Wealth index a composite measure of a household's cumulative living standard is the most influential factors of food insecurity among all. Higher the access to the physical capitals such as 
televisions and bicycles; materials used for housing construction; and drinking water and sanitation facilities decreased the risk of food insecurity. The result is also justified by many others studies (Sseguya, 2009; Guo, 2011; Abdullah et al., 2019).

The variable 'any member(s) having saving account in any financial institution' is considered as the proxy indicator of access to finance and is significant predictor of food insecurity. Access to finance in low-income countries is a key determinant of economic well-being for households (Dey \& Majumder, 2017) and consequently the food security. The fact is also obeyed by the study result. In addition, Chang et al. (2014) also reveals that access to finance is the significant predictor of food security that also validates our result. Mango et al. (2014), and Abdullah et al. (2019) also allied with the study result that remittance is the significant predictor to the food insecurity. Various studies depicted that education of the household head of the household were the significant predictor of food insecurity (Sseguya, 2009; Joshi and Joshi, 2016; Kidane et al., 2005; Abdullah et al., 2019). But in this study, we consider number of members completed secondary education as the educational status of the household and found it significant. Joshi and Joshi (2016), and Bogale (2012) also confirm the study result that family size is the significant predictors of food security status.

\section{CONCLUSION}

Food security is a global challenge and threatens the rural people in developing countries. The aims of the study were to examine the factors that affect the food insecurity status among rural household in Nepal. The outcome variable food insecurity status is in ordinal scale. Due to violation of assumption of proportional odds, multinomial logistic regression was used instead of ordinal logistic regression model and found that all the diagnostic criteria were satisfied. Based on the findings, we can conclude that food insecurity of the household increases with decrease in the wealth index, size of land and number of members of the household completed secondary education, and increase with increase in the family size. This clearly depicts that wealth index and land size of the household, and number of educated members in the family is inversely associated with food insecurity whereas size of the family is directly related. Moreover, the food insecurity of the households decreases with the increase in the household access to bank services.

\section{CONFLICT OF INTEREST}

The author declared that there is no conflict of interest.

\section{ACKNOWLEDGEMENTS}

Authors would like to express sincere gratitude to Prof. Dr. Srijan Lal Shrestha, Prof. Dr. Shankar Pd. Khanal and Associate Prof. Dr. Mrs. Gauri Shrestha for insightful comments and encouragement to complete this paper. 


\section{REFERENCES}

Abdullah, Zhou, D., Shah, T., Ali S., Ahmad, W., Din, I. U., \& Ilyasa, A. (20I9). Factors affecting household food security in rural northern hinterland of Pakistan. Journal of the Saudi Society of Agricultural Sciences, I8(2), 20 I-2 I0. https://doi.org//0.10 I 6/j.jssas.20 I 7.05.003.

Bogale, A. (2012). Vulnerability of smallholder Rural households to food insecurity in Eastern Ethiopia. Food Security, 4, 58I-59I. DOI: 10.1007/s / 257/-0 /2-0208-x

Brant, R. (1990). Assessing proportionality in the proportional odds model for ordinal logistic regression. Biometrics, 46(4), I77I- II78. Retrieved from https://pubmed.ncbi.nlm.nih.gov/2085632/.

Central Bureau of Statistics. (2004). Nepal Living Standards Survey 2003/04, Statistical Report (Vol. II), National Planning Commission Secretariat, Government of Nepal.

Central Bureau of Statistics. (2005). Poverty trends in Nepal (I995-96 and 2003-04). Nepal Planning Commission Secretariat, Government of Nepal.

Central Bureau of Statistics. (2017). Statistical Year Book Nepal 2017. National Planning Commission Secretariat, Government of Nepal.

Chang, Y., Chatterjee, S., \& Kim, J. (2014). Household finance and food insecurity. J. Fam. Econ. Issues, 35(4), 499-5I5. DOI: https://doi.org/l 0.1007/s/ 0834-0/3-9382-z.

Coates, J., Swindale, A., \& Bilinsky, P. (2007). Household food insecurity access scale (HFIAS) for measurement of household food access: Indicator Guide. Washington, D.C.: FHI 360/FANTA, 3.

Dey, S. \& Majumder, S. (20I7). Identifying factors that influence access to banking services in Bangladesh: A household level analysis. The Bangladesh journal of scientific research $30(1-2)$, 8I-89. DOI: 10.3329/bjsr.v30il-2.36/22

Dolgun, A., \& Saracbasi, O. (20I4). Assessing proportionality assumption in the adjacent category logistic regression model. Statistics and its interface, 7, 275-295.

DOI: 10.4310/SII.2014.v7.n2.al2.

El-Habil, A. M. (2012). An Application on Multinomial Logistic Regression Model. Pakistan Journal of Statistics and Operation Research, 8(2), 27I-29I. DOI: 10.18/87/pjsor.v8i2.234.

FAO. (2006). Policy brief, FAO's Agriculture and Development Economics Division (ESA) with support from the FAO Netherlands Partnership Programme (FNPP) and the EC-FAO Food Security Programme, Issue 2. Retrieved from http://www.fao.org/fileadmin/templates/faoitaly/documents/pdf/pdf_Food_Security_Cocept_Note. $p d f$

FAO. (2010). Agriculture and Consumer Production Department-Nutrition and Consumer

Production. Retrieved from http://www.fao.org/ag/agn/nutrition/household_en.stm.

FAO. (20I5). The State of Food Insecurity in the World. Food and Agriculture Organization of the United Nations, Rome.

FAO. (2017). The future of food and agriculture -Trends and challenges. Rome.

GFSI. (2019). Rankings and trends. The Economist Intelligence Unit Limited. Retrieved from https://foodsecurityindex.eiu.com/Index. 
Guo, B. (20II). Household assets and food security: Evidence from the survey of program dynamics. Journal of Family and Economic Issues, 32, 98-I I0. DOI: 10.1007/s I0834-0 I09194-3.

Habidin, N. F., Mohd Zubir, A. F., Mohd Fuzi, N., Md Latip, N. A., \& M.N.A., Azman. (20I5). Sustainable performance measures for Malaysian automotive industry. World Applied Sciences Journal, 33(6), I017-I024, DOI: 10.5829/idosi.wasj.2015.33.06.257.

IBM knowledge Center. (2016). Multinomial Logistic Regression. Retrieved from https://www.ibm.com/support/knowledgecenter/SSLVMB_24.0.0/spss/regression/idh_mnlr.html.

ILO (2007). Key indicators of the labour market (Ed. 9). International Labour Office, 20I6, Geneva. Retrieved from https://www.ilo.org/wcmsp5/groups/public/--dgreports/-stat/documents/publication/wcms_498929.pdf.

Joshi, G. R., \& Joshi, N. B. (2016). Determinants of household food security in the eastern region of Nepal. SAARC J. Agri, I4(2), I74- I88. DOI: http://dx.doi.org//0.3329/sja.v / 4i2.3 / 257.

Kassie, M., Ndiritu, S.W., \& Stage, J. (20I4). What determines gender inequality in household food security in Kenya? Application of exogenous switching treatment regression. World Dev, 56, I53-17I. DOI: https://doi.org//0.1016/j.worlddev.2013.10.025.

Kidane, H., Alemu, Z.G., \& Kundhlande, G. (2005). Causes of household food insecurity in Koredegaga Peasant Association, Oromiya Zone, Ethiopia. Agrekon, 44(4), 543-560. DOI: https://doi.org//0.1080/0303/853.2005.9523727.

Mango, N., Zamasiya, B., Makate, C., Nyikahadzoi, K., \& Siziba S. (2014). Factors influencing household food security among smallholder farmers in the Mudzi district of Zimbabwe. Development Southern Africa, 3 I(4), 625-640. DOI: 10.1080/0376835X.20 I 4.9 I I694.

McCullagh, P. \& Nelder, J. A. (1989). Generalized Linear Models ( $2^{\text {nd }}$ ed.). London, Chapman and Hall.

MoH [Nepal], New ERA,\& ICF. (20I7). Nepal Demographic and Health Survey 2016. Kathmandu, Nepal: Ministry of Health, Nepal.

Nkomoki, W. , Bavorová, M., \& Banout, J. (2019). Factors associated with household food security in Zambia. Sustainability, I I(9), 27I5. DOI:I0.3390/su I I0927I5.

Pant, K. (2013). Climate change and food security in Nepal-Technical paper. The Journal of Agriculture and Environment, I3. DOI: 10.3 I 26/aej.v/3i0.7582.

Quinonez, H., \& Hackett, M. (2008). Measuring household food security: The global experience. Revista de Nutrição, Rev. Nutr., 2I. DOI: https://doi.org// 0.1590/S / 4 I552732008000700004.

Sseguya, H. (2009). "Impact of social capital on food security in southeast Uganda". Graduate Theses and Dissertations, paper 10747. Retrieved from https://www.researchgate.net/publication/24/809739.

WFP and NDRI. (20I0). The Food Security Atlas of Nepal. Kathmandu: WFP/NDRI. 
Reference to this paper should be made as follows:

Shah, S. K. (2020). Multinomial logistic regression model to identify factors associated with food insecurity in rural households in Nepal. Nep. J. Stat, 4, 17-32. 